\title{
INTERDISCIPLINARIDADE: FUNCIONALIDADE OU UTOPIA?
}

MARIA CECILIIA DE SOUZA MINAYO*

\begin{abstract}
RESUMO: Este artigo levanta uma discussão teórica sobre várias visões a respeito de Interdisciplinaridade. Analisa-se a visão humanitária defendida por GUSDORF, que critica o esfacelamento do saber parcelizado, buscando a raíz de um conhecimento integrado e unitário na Grécia antiga. Aborda também o pensamento crítico de CARNEIRO LEÃO e outros autores que refletem sobre a funcionalidade da interdisciplinaridade na ciência e tecnologia modernas. E termina com a teoria da ação comunicativa de HABERMAS que propõe a articulação entre a filosofia, a ciência e o mundo da vida como uma nova forma de relação dialética entre o sujeito e objeto na construção do conhecimento.
\end{abstract}

Trata-se de um artigo que mais propõe questões que soluções, dando pistas para a abordagem de situações concretas para a área da saúde onde não só é crucial a integração de disciplinas como a multiprofissionalidade.

\section{INTRODUÇÃO}

Este artigo trata da questão da interdisciplinaridade, um tema que, como se verá no decorrer da leitura é uma constante epistemológica. Nossas indagações contemporâneas são a reafirmação da utopia de uma integridade perseguida historicamente pela ciência. A preocupação dos grandes sábios tem sido a de que

\footnotetext{
* Professora adjunta da Escola Nacional de Saúde Pública/FIOCRUZ, nas cadeiras de Metodologia da Pesquisa Social em Saúde e Metodologia da Investigação Científica.
} 
a dispersão de conhecimento, se corresponde à divisão de trabalho intelectual, não deveria resultar em contradições entre os pesquisadores e o resultado de seus trabalhos.

No entanto, o termo interdisciplinaridade é confuso e utilizado para se remeter a realidades e propósitos os mais diversos. GUSDORF comenta que, nas reformas universitárias, todos se colocam defendendo o caráter interdisciplinar das instituiçōes de ensino. Para muitos, porém, isso significa apenas juntar várias faculdades no mesmo lugar ou juntar vários especialistas com suas linguagens particulares sentados um ao lado de outros (1978:625). Ele propõe como saida um saber geral e superior, uma "ciência humana" reagrupadora e rearticuladora de um "humanismo convergente."(1978:637)

CARNEIRO LEÃO em recente artigo (1991) para um simpósio na UNESCO critica as "retóricas de persuasão" em tomo da interdisciplinaridade, desvendando as estruturas do conceito como uma "funcionalidade" da ciência ocidental.

HABERMAS, dentro de uma macro-visão aposta numa nova racionalidade a partir do encontro entre filosofia, ciência e mundo da vida, (1988: 465-508) para se contrapor à razão instrumental que domina a sociedade moderna.

$\mathrm{Na}$ verdade ver-se-á que a reivindicação interdisciplinar ora se apresenta como panacéia epistemológica, invocada para curar todos os males que afetam a consciência cientifica moderna; por vezes se fala dela com um ceticismo radical; por vezes, como uma fatalidade própria do avanço técnico e científico.

Mais do que definir o conceito, julgamos importante, para subsidiar as discussões do setor saúde, mostrar as controvérsias e a pluralidade de sentido de 
que se reveste o termo, e as possibilidades que cada interpretação desvenda para a prática cientifica.

\section{A INTERDISCIPLINALIDADE COMO BUSCA DE TOTALIDADE DO CONHECIMENTO}

A interdisciplinalidade como busca de totalidade do conhecimento tem em GUSDORF $(1974,1977)$ seu representante atual maior. Considerado um humanista radical e um retórico idealista, dir-se-ia que o autor usa todas as suas armas para convencer aos cientistas modernos e pós-modernos dos males da fragmentação do saber. Em "Passé, Présent et Avenir de la Recherche Interdisciplinaire" (1977) realiza uma vasta recuperação histórica do conceito em questão, colocando-o como uma exigência central epistemológica da ciência ocidental. Daremos aqui um resumo de seu pensamento.

Segundo Gusdorf a exigência interdisciplinar se inscreve no campo do conhecimento desde os sofistas gregos que já haviam definidos para seus discipulos um programa de "enkuklios paideia" ou seja, de ensinamento circular que cobria a totalidade de disciplinas constitutivas da ordem intelectual. Na Antigüidade, - Museu de Alexandria, centro de cultura helênica para ensino e pesquisa, incarnou por mais de meio século o projeto de agrupamento das ciências e das letras, das artes e das técnicas, reunindo estudiosos e tecnologias de todas as áreas.

Adotado pelos romanos, esse programa enciclopédico foi transmitido aos mestres medievais. A universidade medieval queria ser a comunidade dos mestres, dos mestres e discípulos, assim como a comunidade das disciplinas do conhecimento. A partir do século XIII a instituição confiou à Faculdade de Letras a gestão das "artes liberais" ou seja, disciplinas que garantissem a "liberdade de 
espírito": O TRIVIUM (gramática, retórica e dialética) e o QUADRIVIUM (aritmética, astronomia e música) compondo o conjunto unificado de letras e ciências.

Essa pedagogia da totalidade foi retomada sem ruptura na Renascença sob o domínio do humanismo, sobretudo nos colégios jesuitas até 1760-1770 quando a perseguição a sua ordem religiosa provocou a supressão dessa forma de conceber a organização do conhecimento, que reproduzia o programa milenar dos sofistas gregos.

A preocupação unitária foi também uma das idéias centrais do lluminismo. O progresso das ciências e das técnicas no decorres do século XVIII se inscreveu no horizonte de uma reforma geral da conduta humana. A construção da Enciclopédia sob a direção d'Alembert e Diderot na França ilustra a visão racional de uma unidade na diversidade dos saberes e das práticas. Essa grande obra tenta recuperar a idéia do "Eukuklios Paideia" dos Gregos e dos Romanos enriquecida de todos os aportes das ciências modernas depois da Renascença. A relação do uno e do múltiplos que preside a construção da Enciclopédia está explicita no discurso de abertura da obra por d'Alembert. Segundo o autor, cada disciplina pode ser considerada como desenvolvimento de principios fundamentais, devendo ser possível uma formalização superior, na medida em que o universo para quem sabe contempla-lo é fato único e uma mesma e grande verdade.

No século XIX autores como o historiador romântico Michelet retomam o tema da unidade da ciência mostrando a mútua fecundação possivel entre os campos disciplinares. Sabe-se que o século XIX foi marcado pela expansão do trabalho cientifico. As tecnologias de pesquisas em todos os domínios se enriqueceram prodigiosamente, acompanhadas, em contrapartida, pela multiplicação de abordagens: o tempo dos especialistas chegou e com ele a fragmentação do saber. As certezas se tornaram fatos se impondo 
fragmentariamente. O positivismo tornou-se hegemônico como paradigma do saber e as disciplinas passaram a se afirmar no esplêndido isolamento de suas questões e de suas próprias metodologias, fazendo da linguagem das ciências rigorosas uma espécie absoluta. A pulverização do saber em setores cada vez mais limitados lançou os cientistas numa solidão paradoxal na medida em que perderam o sentido de uma causa comum que os reunia ou seja, o sentido da vida e da verdade do universo como um todo.

O século XIX marcou um recuo interdisciplinar: a consciência científica tornou-se asfixiada pela massa crescente de suas conquistas. A acumulação quantitativa do conhecimento pagou o preço, segundo Gusdorf, do desmantelamento da inteligência.

A forma mais explícita da nova era da fragmentação foi expressa na organização da Universidade Imperial da França, criada por Napoleão em 1808 , separando a faculdade de Letras das faculdades de Ciências e tornando necessária a escolha entre cultura literária ou cultura científica. GUSDORF (1977) é radical na sua crítica a essa forma institucional de organização do saber:

"reduzidas às próprias fontes por uma injustificável divisão do trabalho, a "literária" e a "científica" são cegas pela metade: uma parte considerável do campo epistemológico é para elas como se não existisse, sofrendo ambas de uma amputação fundamental."(p. 618)

Fundada em 1810, a Universidade de Berlim seguiu caminho diferente, tentando criar uma solidariedade orgânica do saber e organizando-se de forma interdisciplinar. A idéia central então defendida era de que cada ordem de conhecimento existe por si mesma mas existe também para os outros na relação com a totalidade do saber. Em 1880, na Alemanha houve uma tentativa de separação entre literatura e ciências a exemplo da instituição napoleônica. 
Na Inglaterra criaram-se as Escolas Politécnicas para se diferenciarem do modelo universitário tradicional. E no final do XIX, a III República Francesa tentou reverter a institucionalização da fragmentação da Universidade Imperial sem grande sucesso.

Para Gusdorf, a crise dos anos 60 na França e no mundo traduziu, num paroxismo de desespero e utopia, a fraqueza das antigas instituições e a exigência de uma reintegração do espaço mental em seu conjunto.

Aproximando-nos mais da nossa realidade, temos um recente estudo de SCHWARTZMAN (1992) sobre a Faculdade de Filosofia da USP que ilustra bem os dilemas da interdisciplinaridade. Instituida em 1934, copiando uma legislação da Itália, organizou-se dentro do modelo clássico de articulação entre ciências, letras e humanidades. Porém iniciou-se com professores franceses advindos de uma concepção bonapartista de ensino e pesquisa; alemães, cuja idéia universitária integradora estava sendo questionada pelo desenvolvimento sobretudo da química; e italianos, cujo formato já foi mencionado.

A idéia central de que a Faculdade de Filosofia servisse de ponto de união e base científica para as demais escolas da nova universidade fracassou desde o início. Na verdade os "filósofos" foram rejeitados pelas faculdades estabelecidas de medicina, agronomia, engenharia e direito e nunca conseguiram se articular com os centros de pesquisa do estado como o Instituto Biológico, o Butantã e o de Pesquisas Tecnológicas.

Com a reforma universitária de 1971 , as ciências naturais buscaram caminhos próprios, criando institutos e departamentos independentes, aproximando-se dos modelos das escolas de pós-graduação americanas, objetivando a formação de cientistas especializados. 
SCHWARTZMAN (1992) comenta que, olhando-se de forma negativa, a Faculdade de Filosofia perdeu as "ciências". Numa visão positiva, manteve-se fiel a seu papel de centro de pensamento político e de crítica social. Porém ficou fragmentada. É importante frisar uma observação final sua, abrindo perspectiva sobre outro ponto de vista:

"se a Universidade ainda retém uma presença intelectual e um papel de centro de reflexão crítica sobre a sociedade como um todo, isto não é, de maneira nenhuma, papel exclusivo ou mesmo privilegiado das antigas faculdade de Filosofia, da USP ou fora dela." (p. 195).

A partir dos fragmentos e testemunhos aqui colocados, ficam claros alguns aspectos para os quais Gusdorf é porta-voz.

Em primeiro lugar a interdisciplinaridade da qual está falando é a articulação entre os dominios das ciências humanas ou sociais e das ciências naturais. É nesse sentido ele faz a crítica à fragmentação e propõe um humanismo radical.

Em relação à fragmentação, Gusdorf cita a frase lapidar de Bois Reymond, celebre fisiologista da Universidade de Berlim, retomada pelo reitor daquela Universidade quando quiseram transformá-la dividindo suas faculdades.

"O estudo exclusivo das ciências da natureza, como qualquer atividade exclusiva, reduz o campo das idéias. As ciências da natureza limitam o horizonte ao que está sob os olhos, ao alcance das mãos, ao que dá experiência imediata de sentido, com uma certeza que parece absoluta. Elas desviam o espirito das especulações gerais e menos certas e o desacostumam de se mover no domínio daquilo que é indeterminado. Num certo sentido estimulamos nelas esta direçăo como uma vantagem 
muito preciosa. Mas quando são consideradas em posição de domínio exclusivo, o espínto se toma pobre de idéias, a imaginação perde suas cores, a alma sua sensibilidade e a conseqüência é uma maneira de ver estreita, seca, dura, afastada das Musas e das Graças". ( GUSDORF, 1977, p. 619)

Assim Gusdorf chama atenção para a prática epistemológica dividida e certos caracteres antropológicos, mostrando que a excessiva especialização provoca uma esclerose mental, o conhecimento deixa de ter relação com o mundo real e dissocia a existência humana. "É alienada e alienante toda ciência que se contente de desintegrar e dissociar seu objeto".

Com Gusdorf estão autores como seu discipulo brasileiro, JAPIASSU (1974) e outro renomado filósofo e cientista francês, CASTORIADIS (1987). Ambos fazem críticas veementes à fragmentação do conhecimento, ao aprisionamento institucional do saber e ao obscurantismo da ciência modema. Japiassu fala da "anarquia intelectual canceriforme" e Castoriadis, da "fabricação do atraso mental e da servidão provocada pelo formalismo. Porém, lembra Castoriadis, que os problemas do conhecimento não podem ser resolvidos independentemente das profundas transformaçōes da organização social e da orientação histórica. Pois o materialismo mecanicista, analisa Japiassu, é que instaura o divórcio entre o conhecimento da natureza e do mundo social.

A proposta de Gusdorf vem da sua própria compreensão de interdisciplinaridade. Para ele, o projeto da interdisicplinaridade, um dos grandes eixos da história do conhecimento evoca a "colocação em comum" em lugar da "justaposição dos saberes", buscando os limites e indo até aos limites das disciplinas, os contomos e os recortes múltiplos, num regime de cooperação e 
diálogo, abertura e fecundação mútua, sem formalismos que neutralizem as significações.

Em nível elementar, explica Gusdorf, a interdisciplinaridade é a primeira exigência de comunicação, pressupondo a inteligibilidade relacional humana. Se cada ciência possui lógica própria, a compreensão desse pluralismo é essencial para uma inteligibilidade diferente.

Colocando as ciências humanas como guardiãs do projeto interdisciplinar Gusdorf faz sua proposta de humanismo convergente e de antropocentrismo absoluto:

"Os sábios modernos deveriam buscar em comum a restauração das significações humanas do conhecimento" (...) "É preciso restaurar a aliança da ciência com a sabedoria" (...) "A significação fundamental da interdisciplinaridade é a de uma chamada à ordem do humano, de um humanismo da pluralidade e da convergência. (GUSDORF, 1977, p. 637)

\section{A INTERDISCIPLINARIDADE COMO "FUNCIONALIDADE" DA CIÊNCIA E TECNOLOGIA}

Totalmente diferente do pensamento de Gusdorf é a visão que CARNEIRO LEÃO (1991) apresenta num trabalho para uma reunião na UNESCO sobre o tema. O autor realiza uma critica da racionalidade da ciência e por extensão, uma crítica contundente à interdisciplinaridade.

Para ele, a ciência nasceu na era moderna como vigência de transformações históricas na busca de uniformização crescente de suas estruturas. 
Ela busca padronizar através de realização controlada, reprocessada e sistematizada do real. Tem uma tendência totalitária, uma dinâmica de expansão absorvente, um movimento de difusão de si mesma que atropelam qualquer diferença e qualquer oposição.

Para Carneiro Leão o conceito central da Ciência (Moderna) é a funcionalidade. Ou seja, a ciência é uma forma de conhecimento que reduz tudo o que está sendo, o que está vindo a ser, a funções, inclusive o sujeito e as relações entre sujeito e objeto.

"Progressivamente a natureza e a história, o indivíduo e a sociedade, 0 dado e o fato, a coisa física e o valor simbólico, os impulsos e as fantasias, tudo foi reduzido a um universo so: o universo dos sujeitos $e$ dos objetos da apresentação e da representação." (CARNEIRO LEÃO, 1991, p. 3)

Por causa da padronização, a ciência transforma o real em dispositivos e assim trabalha no universo das certezas e do controle: controle do caos, das catástrofes, das bifurcações, das singularidades, das surpresas, do inesperado, do imprevisível, do outro.

Para o autor, o primeiro agente da modernidade funcional é a disciplinaridade da pesquisa. Pela disciplina o conhecimento se exerce como processamento de fenômeno, projetando um fato como objeto, modelos para sua apreensão, controle de sua validade, só admitindo como função da verdade, valores operativos. CARNEIRO LEÃO (1991) comenta que ciência e técnica cada vez mais perfazem um único circuito de funcionalidade, vão se apagando as diferenças inclusive entre ambas. Para ele, já não existe também tanta distinção entre ciências naturais, sociais e humanas e nem entre ciência pura ou sistemática 
e aplicada, nem entre ciência e técnica. "O que existe é uma disciplinaridade multi, inter, transdisciplinar". (p. 4)

O autor coloca a problemática da interdisciplinaridade no bojo da reflexão sobre a funcionalidade. "A essência tecnológica do conhecimento moderno surge como alavanca de Arquimedes que desloca e empurra para baixo a avalanche interdisciplinar da informática. Na interdisciplinaridade de suas práticas, a Ciência é que nasce, não da técnica, mas da essência interdisciplinar das tecnologias". (p. 7)

Assim a interdisciplinaridade tal como é vista pelo autor, nada tem a ver com o mundo da vida e com o real concreto. Está, pelo contrário, imbuída de modelos teóricos e processamentos ligados a práticas operatórias. A interdisciplinaridade nada mais se torna do que uma resultante do desenvolvimento das ciências e da técnica dentro da mesma lógica de funcionalidade: está igualmente comprometida com a transformação do real em objeto e da objetividade em operacionalidade.

As questões atuais da ciência e da técnica, argumenta Carneiro Leão, só podem ser desenvolvidas na e pela interdisciplinaridade e transdisciplinaridade de seus feitos e fatos que se recolhem e se concentram na funcionalidade, "de um dado conjunto de informações se deduzem conjecturas operatórias que se integram interdisciplinarmente em sistemas de alternativas em transformação. automação elimina as alternativas não eficazes remetendo para a dedução de novas conjecturas: o jogo recomeça (p. 8)

Fica claro que o ponto de partida e o argumento de Carneiro Leão são totalmente diferentes daqueles que preocupam Gusdorf. $O$ autor em questão analisa as entranhas da ciência e está menos envolvido em mostrar os problemas 
da fragmentação da ciência e mais decidido a questionar essa forma histórica de conhecimento que afasta o ser humano da sua essencialidade, ao padronizar a busca da verdade, ao nivelar a cultura e discriminar a diferença, $o$ autor.

A interdisciplinaridade que ele conceitua não é a articulação entre ciências sociais e naturais em busca de um "humanismo radical". Para ele, a interdisciplinaridade é uma construção funcional dada pelo avanço da ciência e intrínseca a ela. E desse ponto de vista, CARNEIRO LEÃO critica "qualquer tática retórica de persuasão" em favor da cooperação das disciplinas porque os

"problemas de inter e transdisciplinaridade se restringem ao funcionamento da ciência constituída, a suas funções de equilíbrio, a seus mecanismos automáticos, deixando de fora a interação entre ciência e realidade humana e da natureza na construção do mundo."(p. 9)

O autor termina sua análise fazendo uma crítica radical à importação dos modelos culturais do $1^{\circ}$ Mundo para $\circ 3^{\circ}$ Mundo (visto do ponto de vista histórico-cultural) mostrando que são as questões do poder e da dominação com que mais nos acenam as retóricas atuais da inter e da transdisciplinaridade "importadas" sob a forma de modelos econômicos, paradigmas políticos, recursos tecnológicos e matrizes de conhecimento. Mostrando que no Terceiro Mundo a pobreza, a miséria e a fome são os problemas mais radicais, invocando a "diferença", o "ser outro", Carneiro Leão faz uma provocação aos cientistas para que percebam o resultado da importação de modelos cientificos: na América Latina o investimento dominador fracassou. Temos como resposta baixo desempenho econômico, pouca satisfação social, alta instabilidade política, nenhuma originalidade cultural. 
Em seu trabalho "Qu'est ce que l'interdisciplinarite?" SINACEUR (1977) como CARNEIRO LEÃO (1991), se coloca igualmente numa posição crítica, analisando o tema a partir do interior do campo científico e também das influências que sobre ela exerce o poder. Os pontos de partida de ambos os autores são diferentes. Sinaceur tem uma perspectiva positiva em relação à ciência sobretudo nos seus processos originais.

$O$ autor defende a idéia de que a interdisciplinaridade caracterizou todas as disciplinas em seu nascedouro. A revolução galileana, por exemplo, constituiuse na conjunção da matemática e da física. Da mesma forma, a sociologia histórica veio de uma convergência multi-setorial entre a enquete histórica e social, da história das ciências, da técnica e das idéias.

Sinaceur comenta que a complexidade de conhecimentos das ciências em seu nascimento era fruto de seus criadores, espíritos abertos, sábios curiosos, ávidos de se aperfeiçoarem, e trabalhadores, tanto no sentido puro como aplicado de suas disciplinas. Isso esconde, segundo seu ponto de vista, uma condição essencial do conhecimento interdisciplinar: a competência nos domínios chamados a cooperar. Para esses sábios era evidente que a relação entre duas disciplina era tão essencial que não necessitava ser organizada, era tão interna que dispensava explicações. Neste sentido a interdisciplinaridade torna-se um campo definido de uma disciplina interdisciplinar. Em outras palavras, a interdisciplinaridade só obtém êxito como forma de conhecimento e prática cientifica na medida em que a disciplina utilizadora (e igualmente, o sujeito que a prática) se apropria da disciplina utilizada passando rigorosamente por dentro da sua problemática:

"Isso implica que a colaboração entre duas disciplinas exige a dupla competência e a interdisciplinaridade exige igualmente a competência 
nas disciplinas que ela coloca em colaboração."(SINACEUR, 1977, p. 621)

Para esse autor há um sentido interno da interdisciplinaridade na constituição da disciplina. Mas há também outro sentido exógeno. Assim como Carneiro Leão articula a interdisciplinaridade ao desenvolvimento da ciência para a funcionalidade dela própria e para a criação de seu mundo próprio, Sinaceur articula a prática interdisciplinar à funcionalidade do poder e nesses termos à pesquisa operacional. Por isso há na interdisciplinaridade uma exterioridade da decisão que pronuncia sobre dados e elementos de informação de forma aleatória: articulam-se dois termos de natureza e lógica diferentes, ou seja, conhecimentos especializados e poder decisório.

Segundo Sinaceur a interdisciplinaridade como construção "exterior" revela uma característica de nossa época, ou seja, a integração social do saber ao poder através do conhecimento aplicável, o único capaz de guiá-lo na formação de programas que dêem segurança a seu exercício. Assim, comenta o autor, a interdisciplinaridade é mais um sintoma do que emanação de uma tendência de nossa civilização. Ela não é a emergência de uma situação de fragmentação e sim, pelo contrário, o sinal de preferência por decisão informadas, apoiadas sobre pontos de vista tecnicamente fundados, sobre o desejo de decidir a partir de cenários construidos sobre conhecimentos precisos.

A interdisciplinaridade como exterioridade se instaura no terreno das ciências básicas de uma forma diferente daquela que se dá nas políticas públicas. Por exemplo, a biologia molecular é interdisciplinar porque se constitui sobre a bioquímica: ela não tem que explicitar essa articulação. Tratando-se porém de aplicar uma descoberta desse campo, sobre ela se abre um juizo externo que se 
apoia na filosofia, na ética, na história, etc... fazendo-se incluir nos objetivos da pesquisa o questionamento de sua própria aplicação.

Desta forma a atitude interdisciplinar frente a necessidades sociais concretas, segundo Sinaceur, consiste na procura de correlação, irredutivel à simples justaposição, sobre a coleção de vereditos particulares enunciados a partir de uma especialidade. É a busca da síntese com finalidade prática que determina 0 recorte do objeto e se consolida sobretudo na pesquisa operacional.

A pesquisa operacional consiste na tematização dos problemas e sua organização metódica nos setores onde há intervenção humana. Noutros termos, dentro da formulação de políticas públicas. Foi definida como método científico para fornecer aos organismos de direção as bases quantitativas das decisões que concernem ao setor que comandam.

Sinaceur é cético quanto à discussão da interdisciplinaridade de forma acadêmica.

"Quando se transfere para a Universidade, lugar onde não se decide sobre os problemas que se estudam, a interdisciplinaridade se perde na reflexão sobre relações entre disciplinas, entre especialidades, e há a tentação de se trabalhar aí sobre as premissas de uma nova filosofia da síntese, da coordenação e da unificação. "(SINACEUR, 1977, p. 625)

Completando seu raciocínio crítico Sinaceur acrescenta:

"Os mais lúcidos conduzem as pesquisas de confrontação interdisciplinar sobre problemas de significado decisório e político: a paz, o ambiente, a escolarização, o impacto da ciência e da tecnologia. Inversamente e pela mesma razão, a interdisciplinaridade se impõe em 
todos os lugares onde as especialidade são institucionalizadas nos setores especializados, cuja coordenação é ao mesmo tempo elaboração de uma sintese especifica de informações heterogêneas, o objetivo sendo sempre, um objetivo de ação."(625)

Como se pode deduzir, partindo de pontos de vista totalmente diferentes, Carneiro Leão e Sinaceur retiram o tapete do idealismo e da "vontade intelectual" como espaço para os pés na interdisciplinaridade, numa crítica implícita ao "humanismo de convergência" das ciências como propõe Gusdorf.

\section{A INTERDISCIPLINARIDADE COMO RAZÃO COMUNICATIVA}

Como se pode perceber pelos termos, estamos frente a um tema habermasiano. Diferente de Carneiro Leão, Habermas crítica a ciência, mas parte de sua positividade, como bem o mostra SIEBENEICHLER (1989) em "Encontros e desencontros no caminho da interdisciplinaridade."

Na teoria do agir comunicativo HABERMAS (1988) desenvolve como uma das idéias centrais, a crítica ao estreitamento do conceito de racionalidade às suas dimensões cognitivo-instrumentais, deixando de fora os elementos éticonormativos e estéticos-subjetivos. Nisso ele se irmana aos teóricos da Escola de Frankfurt como Adorno e Horkheimer. Partindo do principio de que nossa sociedade tem que dar um salto de qualidade para reverter esse quadro, Habermas pensa a saida através da filosofia, como também queria Gusdorf. Porém, segundo Habermas, trata-se de construir uma filosofia crítica que se apoie em dois eixos complementares: a) atividade comunicativa, b) razão comunicativa.

Nesse sentido a filosofia não reduziria seu papel a um posicionamento apenas critico e negativo em relação à sociedade contemporânea, mas ampliaria 
sua atividade num labor cooperativo, fazendo a mediação entre a filosofia e as ciências, entre a cultura sofisticada dos especialistas nas ciências e técnica e o mundo vital. Portanto, aqui se supõe, em primeiro lugar, a transformação da filosofia em crítica; em seguida, um processo de cooperação interdisciplinar. A filosofia declina de seu espaço de tribunal da razão, para ser mediadora entre os "experts" das ciências e o mundo da vida cotidiana.

A cooperação interdisciplinar manteria atitudes críticas fundamentais: de um lado, em relação à racionalidade técnica, instrumental e à ideologia tecnocrática; de outro, em relação à tentativa de colonização do mundo vital pela ciência e pelas tecnologias sofisticadas e à ideologia funcionalista que as justifica.

A mudança de paradigma proposta leva a vivenciar uma tensão paradoxal entre cooperação interdisciplinar e crítica de pretensão de validade das disciplinas; entre filosofia da consciência, onde o sujeito se refere aos objetos para representá-los como são ou para intervir neles e torná-los como deveriam ser; e a filosofia do agir comunicativo, onde o sujeito cognoscente, no seu processo de desenvolvimento é obrigado a entender-se e entender-se com os outros, sobre o significado da ação. No primeiro caso, o sujeito é aquele que se relaciona externamente com os objetos para conhecê-los, para agir e para dominá-los. No segundo caso, o sujeito está em interação com outros sujeitos, preocupados todos com o que pode significar conhecer objetos, pessoas e coisas.

A abordagem tal como pensada por HARBEMAS (1988) passa por três pressupostos:

a) Parte do princípio de que a ciência (seja qual for) não tem um começo ou um ponto de apoio totalmente certo e seguro que a conduziria a uma evidência última. Não possuindo uma fundamentação transcendental e infalivel, o caminho de construção do conhecimento é o processo racional de entendimento desse 
saber com outros saberes em sua relação com o mundo vivido, com a vida prática;

b) As ciências abstratas e a filosofia têm que entrar em entendimento com as ciências empíricas, buscando sempre criticar e avaliar os pressupostos gerais de determinado saber e o discurso argumentativo, relacionando as descobertas obtidas, à questão ética e à subjetividade. Haveria então uma busca de unidade de razão, expondo o trabalho científico ao controle direto de um "coro de muitas vozes" através da proposta interdisciplinar. Essa "exposição" requer, de um lado, o reconhecimento dos limites dos pesquisadores, das disciplinas e dos próprios campos de conhecimento; de outro, um diálogo critico que, ao articular o trânsito das diferentes linguagens, aponte o rumo de um "humanismo radical" como fim de todo conhecimento.

c) Em terceiro lugar, a teoria da racionalidade de Habermas está referida incondicionalmente às estruturas do mundo cotidiano onde se articulam os produtos da ciência e da técnica como cultura, a cultura no seu sentido mais amplo e a linguagem dos leigos no cotidiano onde os problemas do mundo contemporâneo são experimentados por todos nós (inclusive pelos cientistas) com a própria força explosiva da vida.

O conceito de razão comunicativa, seguindo o raciocínio assinalado acima, é para Habermas, sinônimo de agir comunicativo, ou seja, tradução de uma postura ativa de interrelação e diálogo interdisciplinar. Mais ainda, (da mesma forma que na fenomenologia sociológica de Schutz e na hermenêutica de Gadamer), a ação e a praxis comunicativa comuns e quotidianas são erigidas ao altar da dignidade epistemológica, como guardiãs e avaliadoras da praxis acadêmica. Por isso, na teoria do agir comunicativo, a racionalidade não pode ser obtida na meditação monológica e solitária de um cientista. Essa comunicação tem 
que ser construida sobre as bases de uma coerência de linguagem entre as teorias distintas que possam ser tratadas como fragmentos teóricos de uma abordagem mais ampla.

No processo de construção comunicativa há então um duplo movimento. Em primeiro lugar, o diálogo da aproximação e da possibilidade que leva a uma busca de aprofundamento das disciplinas no que tange aos conceitos fundamentais. Em segundo lugar, uma busca de sintese que se apropria de "fragmentos convergentes" conseguidos sobretudo na transitiva complementaridade dos conceitos. Desta forma há uma busca de encontro através de questōes comuns e a construção de um saber que se supera e se amplia em relação à disciplina original.

Um dos temas que sobressai desta reflexão é a questão da validade. Ela é colocada aqui, dentro de outros parâmetros. Em primeiro lugar, o "princípio da hierarquia" entre as ciências substitui-se pelo "princípio da cooperação" possibilitando a transitividade interna na discussão dos conceitos e linguagens. Em segundo lugar, a "validade interna" não responde sozinha pelo valor do conhecimento como tem sido colocado tradicionalmente.

A validação científica passa a abranger pelo menos três aspectos: a) a validade proposicional, isto é, aquela que verifica a relevância do objeto e da proposta, tanto para o campo da ciência ao que dizem respeito, como em nível da relação com as necessidades reais do mundo vivido; b) a validade normativa que abrange os aspectos de adequação de métodos e técnicas ao desenvolvimento do objeto e/ou da proposição; c) a validade subjetiva, ou seja, aquela que confere significado às descobertas científicas do ponto de vista ético e benéfico à sociedade, através da argumentação no "diálogo de muitas vozes" incluindo-se o mundo da vida. 


\section{CONSIDERAÇÕES FINAIS}

Como se menciona na introdução, torna-se praticamente impossivel conceituar consensualmente a interdisciplinaridade. De um lado há uma "interdisciplinaridade implícita" não dita, interna, própria da racionalidade científica que, pelo avanço de conhecimentos acaba criando disciplinas. Por outro lado. há um uso interdisciplinar constituído externamente através de campos operativos que articulam ciência, técnica e política, sobretudo através de intervençöes sociais como é o caso da saúde. Esse duplo movimento pode ser datado em seu incremento a partir da $2^{\mathrm{a}}$ Guerra Mundial pelo desenvolvimento da informática e pelo crescimento da intervenção do Estado na Sociedade.

Nas universidades, 0 debate, quando existe, se concentra no diagnóstico sobre a excessiva especialização e a impotência unidisciplinar de responder às pretensões do conhecimento. A esse respeito SINACEUR (1977) menciona a "tentação da síntese precipitada". Frente ao que foi dito talvez se possa chegar a alguns pontos comuns, mesmo acolhendo o contraditório dessa controvérsia teórica-metodológica:

a) a interdisciplinaridade não pode ser acolhida ingenuamente como uma panacéia para os males do campo científico;

b) o conceito em questão, embora seja uma constante nas preocupações epistemológicas porque aparece em todas as épocas históricas no campo da ciência, deve receber um tratamento diferenciado no mundo contemporâneo levando-se em conta as condições de produção do saber.

c) atualmente do ponto de vista prático, a experiência tem mostrado que, frente a temas complexos impossiveis de serem tratados isoladamente, os êxitos dependem : 1) de reunião de pessoas capazes de dialogar e dispostas a isso; 2) 
de reunião de pessoas competentes em suas áreas disciplinares dispostas a compreender a problemática específica da matéria de colaboração; 3)em conseqüência, do diálogo e competência redundam a discussão de conceitos, triangulação metodológica e colaboração na análise dos resultados. Além, evidentemente, da discussão do conteúdo social e ético da produção científica.

d) Por fim, é necessários frisar que as funcionalidades cada vez mais velozes na prática científica e as controvérsias sobre inter e transdisciplinaridade não podem escamotear um debate crítico sobre o esfacelamento do conhecimento, os encastelamentos de saber e poder, a alienação do processo de conhecimento em relação ao mundo da vida. A universidade como qualquer instituição que se mantém através da verba pública tem um encontro marcado com 0 desenvolvimento científico e tecnológico do pais, mas também com o drama social no qual está imersa a maioria da população.

\section{REFERÊNCIAS BIBLIOGRÁFICAS}

1. CARNEIRO LEÃO, E. Para uma critica da interdisciplinaridade. Tempo Bras., 1991. [no prelo]

2. CASTORIADES, C. As encruzilhadas do labininto. Rio de Janeiro, Paz e Terra, 1987.

3. GUSDORF, G. Introduction aux sciences humaines. $2^{\text {a }}$. ed., Paris, Éditions Ophrys, 1974.

4. GUSDORF, G. Present, passé avenir de la recherche interdisciplinaire. Rev. Int. de Sciences Sociales. 29:627-48, 1977.

5. HABERMAS, J. Teoria de la acción comunicativa. $2^{\text {a }}$. ed., Madrid, Taurus, 1988.

6. JAPIASSU, H. Interdisciplinaridade e patologia do saber. Rio de Janeiro, Imago, 1974. 
7. SCHWARTZMAN, S. O sentido da interdisciplinaridade. Novos Estudos CEBRAP. 32:191-8, 1992.

8. SIEBENEICHLER, F. Encontros e desencontros no caminho da interdisciplinaridade. Tempo Bras. 98:153-80, 1989.

9. SINACEUR, M. A. Qu'est ce que l'interdisciplinarité? Rev. Inte Sci. Soci.. 29:61726, 1977. 